\title{
THE ROLE OF CIVIL SOCIETY IN HEALTH COMMUNICATION
}

\author{
Mr. Satnam Singh \\ Ph.D. Research Scholar, \\ Department of Journalism \& Mass Communication, M D University, and \\ Assistant Professor, Amity School of Communication, \\ Amity University Madhya Pradesh, Maharajpura Dang, Gwalior \\ Mr. Siddharth Singh Tomar \\ Department of Biotechnology, \\ Amity University Madhya Pradesh, Maharajpura Dang, Gwalior
}

\begin{abstract}
Health Communication is an emerging field, it involves the examination of various communication models and techniques used by healthcare professionals and policymakers to communicate health and influence the health-related behavior of the public. It is an interdisciplinary niche where social sciences, psychology, life sciences, and communication studies work in close association. It is also important to understand different theories of mass communication while working out a suitable health communication strategy. Various professionals and organizations are involved in the process of communicating health to society, civil society is the prime stakeholder in this process. It is clear from the analysis of historical and contemporary data that civil society has contributed greatly over a period of time in communicating health to the people. Civil society also had contributed in mobilizing, rights advocacy, and community monitoring of health centers and schemes. We studied the content of various civil society organizations having a rural footprint to ascertain their impact on health communication. The healthcare ecosystem in India is rapidly changing, in the view of continuous decrease in state spending over the healthcare role of civil society became increasingly crucial, so it is very important to ensure their greater participation at all levels of policy making and in implementation as well.
\end{abstract}

Keywords: Health Communication, Civil Society, NGOs, Rural Health, Community, Public Health

\section{Introduction}

Health communication is a dynamic subject and because of its multidisciplinary nature, the definition of health communication is also continuously evolving. Different researchers have different perspectives on this subject. However, there is a consensus about the crucial role which health communication plays in supporting the individuals, creating awareness, and influencing policymakers for making informed decisions. The Center for Disease Control and Prevention (CDC) defines health communication as 'the study and use of communication strategies to inform and influence individual and community decisions that enhance health' (Riegelman, 2001)

Civil society is a group of concerned citizens working for a shared objective which is generally oriented towards the welfare of people. Civil society uses communication tools for mobilizing support, achieving the objectives and creating a conducive discourse for their ideas. When the civil society starts pursuing some health-related issues and starts communicating then, then the theories of health, communication, and social sciences begin operating together for a shared objective. Human evolution is evident that human health is directly linked with the effectiveness of communication between human beings. As humans started developing complex societies, they started acquiring knowledge. Mere acquisition of health-related knowledge is not enough; that must be communicated to the audiences. This exchange can be termed as Health Communication. This whole process has many stakeholders, factors, and actors too. Each of them has its own importance. In this paper, we are trying to study the role of the Indian civil society in the process of health communication.

During the colonial era, the Indian healthcare system was a diverse mix of Native medical practices and newly introduced western medicine. Initially, Indians were reluctant 
towards adopting the western medicines as they were very doubtful about the use of animal products in the making of these medicines, but the outbreak of epidemics specifically the Sixth-Cholera outbreak of 1899 which was believed to be originated from India during Kumbh Mela at Haridwar (Arnold D., 1986) played a decisive role in changing the notion of Indians about western medicine. The British government found it very difficult to communicate the role of mosquitoes in spreading malaria, as the idea of vector-borne disease was an alien concept for Indians. But, the Indian Civil Society by then (which consisted of the wealthy elite and were respected by the masses), articulated the principles of hygiene, sanitation, and Germ Theory of Disease in a manner that was comprehensible to the common Indians. Their versions of health-related information were more acceptable to the masses than the versions being propagated by the colonial government. This was not the isolated example of the role and significance of civil society then, but actually the important and necessary component of health communication and development of the society. There are many examples in modern times too, which highlights the positive impact of the role of civil society in the field of health communication. As we learned so far that the "Civil society and nongovernmental organizations (NGOs) have the power to influence individual behavior and the organizations that are involved in a healthy diet and promotion of physical exercise." (WHO, 2020) According to the World Health Organization they have been seen as collaborators and partners who can support the implementation of health communication strategies by:

- leading grass-roots mobilizations and advocating the healthy life practices related but not limited to diets and physical activities etc.;

- supporting the preventive measures through exchange and dissemination of information on various diseases and programs;

- forming community and pressure groups to promote healthy practices through dissemination of information;

- advocating and supporting healthpromoting schemes, policies, and health education campaigns;
- monitoring and engaging with the audiences and other stakeholders;

- contributing in working out some practical solutions for the problems.

\section{Historical Perspective and Immediate Challenges}

Provincial governments set up various malaria hospitals in villages of Bihar and Bengal where Indian Doctors were posted, other than providing treatment these rural malaria centers played a pivotal role in spreading general health awareness. Newspapers of colonial India regularly covered Healthrelated topics and encouraged the masses for using government health care facilities. Quackery is one of the major challenges before a healthy Indian society even in the 21st century, one can assume its prevalence in colonial India. Indian media along with the civil society played an important role to counter the problem of quackery and significantly reduced the prevailing trust deficit for western medicine. In Postindependence India various Health campaigns were immediately launched by the New Government. The immediate challenges before the new government were High Mother and Infant Mortality Rates, Frequent Epidemics, Leprosy, Tuberculosis, vector-borne diseases (Malaria and Encephalitis), lack of vaccination facilities, and the Problem of widespread malnutrition. To share the information about government schemes, the government involved civil society organizations that were already working in the healthcare sector.

The malaria eradication program of India was the world's one of the most intensive antimalaria campaigns, by 1958 around 8,704 malaria squads were operational, and around 438 million houses were sprayed with DDT. Due to this widespread campaign, the recorded cases of malaria fell from 75 million in 1951 to 50,000 in 1961 (Amrith, S. S. 2009) This feat was achieved by involving local stakeholders such as panchayats, religious institutions, and community organizations while working in Indian villages.

The cooperative society movement started gaining pace in India from 1950. There are more than 5 lakh such organizations registered in India. Health awareness and access to public health schemes were also incorporated as components in various projects. Cooperative anti-malaria society was 
established in Bengal by Dr. G.C. Chatterjee in 1912; by the end of the 1930s, 2000 such societies were affiliated to it. Cooperative Union of India undertook various projects in which members of the cooperatives work with primary health centers for gender sensitization and promoting Rural Health. Several programs were regularly conducted to create awareness about polio, malaria, child, and mother health, Tuberculosis, and AIDS. Selfhelp groups (SHGs) are the small groups generally consisting of 10-50 women; they pool their resources and start an enterprise. The profit is distributed among the members. These self-help groups are not only doing financial or business activities, but many of them are also focusing on the health sector. Many SHGs in India are now working on the subject of menstrual health and hygiene. (Gupta M. K., Kumar D., \& Visengrawala F. 2015) They are producing sanitary napkins and creating awareness about reproductive health amongst women living in Indian Villages. For that, they are adopting innovative communication strategies which include street plays, door to door meetings, traditional wall paintings, and even religious and social gatherings are being used for normalizing a topic that is largely considered as a taboo in the Indian society.

The social media is also playing a vital role in promoting health-related information, the reach of social media in India has grown exponentially even in the rural areas Thus, it is being extensively used by the government organizations and civil society for communicating health. Social media empowers and educates masses about their rights and government policies; it has a farreaching impact across a great social and cultural diversity, it also empowers certain marginalized groups such as women to raise their issues (Marcondes de Moraes et al. 2020) On the other side, the same social media ecosystem is also facilitating the unchecked flow of health-related misinformation. India needs a proactive strategy at the central level to control this misinformation. Despite the progress made in the health sector, India is still facing various challenges, and the country needs to go a long way to meet global healthcare standards. For this objective India requires a comprehensive health communication strategy. This strategy must be in sync with the country's social, cultural, and linguistic diversity; involving civil society is important for creating a receptive discourse and disseminating the information to the masses.

\section{Key Areas of Health Communication Doctor-Patient Communication}

Effective Doctor-Patient communication is an important activity to guarantee high patient satisfaction levels. This activity thus cannot be delegated. The skills required by a physician for this purpose include listening to a patient's concerns actively and a proper understanding of the patient's psychology. Uncertainty or absence of feedback, information, and proper explanation from the physician leads to dissatisfaction and higher anxiety levels of patients. (Anat, D. S, 2010) physicians generally fail evaluating the information and details which are to be shared with the Patient. A study shows that $45 \%$ of the patient's concerns and $54 \%$ of patient's complaints are not addressed by the doctor up to satisfactory levels. The correlation between the quality of health communication and its impact over health indicators of the patient is also established; it was observed that the reduction of blood pressure in patients was significant when they were allowed to express their concerns without any interruption. (Stewart, M. A. 1995) Generally, the patients while narrating the problems are interrupted by the Doctors, which adversely affects the overall communication. In India the workload on physicians is very high, thus they cannot spare much time for detailed interaction with patients. This creates a communication barrier between the patient and the Doctor, which adversely reflects on patient satisfaction levels. The effectiveness of diagnosis and therapy also suffers. Therefore, it is required to incorporate communication skills as a compulsory subject in the medical curriculum in India.

\section{Interpersonal Communication: At Hospitals}

Hospitals are very diverse ecosystems where individuals from different social, economic, educational, and linguistic backgrounds interact and interoperate. The objective of all healthcare professionals working at hospitals is to provide proper healthcare to the patients. However, it is also observed that due to such diverse backgrounds, healthcare professionals face difficulty while working as a team. They are unable to communicate effectively, due to 
which the team output suffers. For example, if a physician is required to communicate with a diagnosis lab technician it is very much possible that both of them will have different perspectives about the similar subjects and they will use their different jargons to communicate about the subject. This will make communication less efficient and more ambiguous. In the Indian scenario, the profession of a person has a great impact on his social status and vice versa. So, it is very much possible that other than professional barriers these socioeconomic barriers can also hamper the communication process. Regional representation is also very much present in India, which means in a certain profession the majority of the professionals belong to a certain region. This regionalism sometimes creates linguistic barriers during communication. For example; in India, more than half of nursing institutions and colleges are located in the southern part of the country. (Rao K.D, 2017; WHO) Kerala with a population of $3.1 \%$ accounts for $38 \%$ of medically qualified nurses in India. (Anand S., Fan V, 2016; WHO)

\section{Communicating Health to Society}

Health communication is not only limited to the exchange of information between healthcare professionals, it is equally important to communicate the knowledge to the masses. So almost every theory of mass communication applies while communicating health to society. The theory of cultivation states that exposure to any medium of communication cultivates the perception of reality of the recipient. (Mosharafa E., 2015) It has three entities: Institutions, Public, and messages. The health communication also conforms to this theory of cultivation, which means the exposure of the message containing health information "cultivates" its perception, this cultivated perception creates a conclusive understanding of the subject among the masses. Agenda Setting Theory highlights about the power of media to influence the priorities of the common public, (Razinah, N., \& Zain, M. 2017) thus when we co-relate it with health communication, we can conclude that health communication can influence the masses to prioritize the healthcare-related subjects in their discourse. It is not only applicable to the masses, but it also holds in the case of policymakers as the media can influence them too. Neuman's Spiral of Silence theory (Neumann E.N, 1974) explains how favorable public opinions shape discourse, ultimately making it the representation of most favorable ideas for the majority, if healthrelated message/content is articulated in a way that is acceptable to the masses then according to this theory the acceptability of that message increases. The semiotic theory is also applicable in the case of health communication, (Curtin B., 2006) healthrelated content usually contains a lot of graphics, symbols, and illustrations. And these symbols are open for interpretation. As there is no concept of an exact reading of symbols. So, these symbols should be selected carefully to make the content less ambiguous and more effective.

\section{Health Communication in Education}

Through health education individuals learn to maintain, promote, and restore health (Raingruber B, 2004) It is also defined as an experience through which the voluntary adoption of conducive behavior for healthcare is promoted. The focus is to provide adequate knowledge by using that people can make informed healthcare choices. The health communication must focus on encouraging people to adopt a healthy lifestyle, to inform them about various government schemes and health services, educate them about their rights as a citizen and to ensure community participation in the activities such as vaccination programs and health surveys. Content created for health communication for education is very interdisciplinary. It includes principles of Biology like immunization, child gap, menstrual hygiene, respiratory problems, nutrition, and lifestyle disorders. Principles of psychology for promoting community mental health. Principles of law and economics for policy making, are also widely included in developing content for health education. This interdisciplinary nature of content helps in promoting health education across diverse social groups and empowers them to make an informed decision.

\section{Health Communication in Public Health}

Public health as defined by WHO "the art and science of preventing disease, prolonging life and promoting health through the organized efforts of society" (Acheson, 1988; WHO) These objectives of public health could be achieved by promoting healthy lifestyles, prevention of diseases, identification and 
eradication of potential public health hazards. Public health focuses on promoting health equity and health equality. Public health workers constantly try to prevent healthcare problems. They also guide the policymakers and administration of emerging research areas. According to the Essential health services framework, 2014; CDC 'the public health system includes all private and public entities which can contribute towards the delivery of essential health services.'

Going by the above definitions of public health and public health systems it is clear that Civil society has a very great role to play in the delivery of public health. Civil society through health communication can drive policy change and create awareness, can influence the popular beliefs and thus facilitate social change, help to establish new standards, create a receptive environment for new research or therapy, advocate equal access and promote compliance by improving patient-provider relationships.

However, health communication cannot solve problems such as lack of infrastructure and the unavailability of trained human resources. Similar to other domains of communication it is not immune against external pressures and misinformation. It is not always effective in communicating every kind of message to every kind of audience. A distorted or ambiguous message could have undesirable consequences. In India due to the presence of diverse cultural, social, economic, and linguistic identities the probability of miscommunication increases. For solving this problem, a dedicated and decentralized communication strategy is needed which can have acceptability across the nation and deliver the message effectively. Following an integrated approach is very crucial in modern communication processes, the coordinated approach of modern integrated marketing communication (MIMC) could also be used in communicating health to the society. (Kushwah et al. 2020)

\section{METHODOLOGY}

The objective of the paper is to ascertain the role of civil society organizations in health communication. This study is totally based on secondary data and content analysis of the aforementioned organizations. We focused on the organizations with rural footprints and evaluated the impact which they had created. We studied \& analyzed some of the policy decisions of the government of India and international organizations like WHO. Upcoming challenges and present trends in the field of health communication were also studied.

\section{Understanding the Role of Civil Society organizations}

The term civil society is used in the sense of 1) as the collaboration of non-governmental organizations and institutions which represent the interests and will of citizens or 2) individuals and organizations in a society which are independent of the government and advocating the interest of the citizens. While tracing back the evolution of modern civil societies during their initial years we can easily notice their close relationship with the state. The state "allowed" civil societies to exist for ensuring the legitimacy of its actions; the state also communicated its agenda to the masses through civil societies. In earlier days civil societies acted as the extended arm of the state but with lesser power of coercion and enforcement.

The term "civil society" dates back to Aristotle defining it as koinōnía politikế (Frost R., 2017) which translates into "political community" this establishes the initial understanding of civil society as a political entity. As the democratic system of governance grew popular around the world, the definition and objectives of civil society started changing. In a democratic system the place of the political community was taken over by a more formal organization known as the "political party" also the association between civil society and government ceased to exist and the civil society became independent from the state. Now the members of civil society don't need to go along with the policies of the state. Despite this dissociation, the objectives of civil society and the objectives of the state still usually converge and they find some common grounds to work, the state still uses civil society for legitimizing its policies and to compensate for the inefficiency of its machinery.

The major problem which a state usually faces is to communicate effectively with the masses. This problem arises due to a prevailing disconnect between the aspirations and needs 
of citizens and the policies of the state. To bridge this, disconnect, civil society is widely used by the state, providing healthcare is one of the major areas where the state focuses its policy and resources, but the outcome in this sector is generally poor. The evident reason for this problem is that people take healthcare as something personal, they consider a lot of factors like affordability, quality, safety, accessibility, and acceptability before taking a healthcare decision, (Mosadeghrad, A. M. 2014) thus the government/state despite having all the resources and machinery is simply incapable of communicating healthcare effectively because of the disconnect and prevailing trust deficit as discussed previously. In this situation, civil society organizations play a major role in communicating healthcare to the masses. Members of these organizations generally come from the local community, they speak the local language, they are aware of local cultural sensitivities and they have first-hand knowledge regarding the demography of the area. Members of civil society organizations tend to develop a friendly rapport with the local community which makes the process of communication relatively effective. Civil society organizations have a sympathetic attitude towards the problem which motivates them to think of a widely accepted solution to the problem. Civil society organizations involve the stakeholders at every stage of planning and execution of the project. They try to negotiate with the stakeholders and take their feedback frequently. Their execution strategy is not very rigid, unlike government projects, there is a scope of course correction according to the feedback received. They also play their role as whistleblowers when they find some inefficiency or corruption at the part of the government. We can understand the process of community monitoring from following figure:

Figure 1: Community Monitoring Structure \& Flow Chart

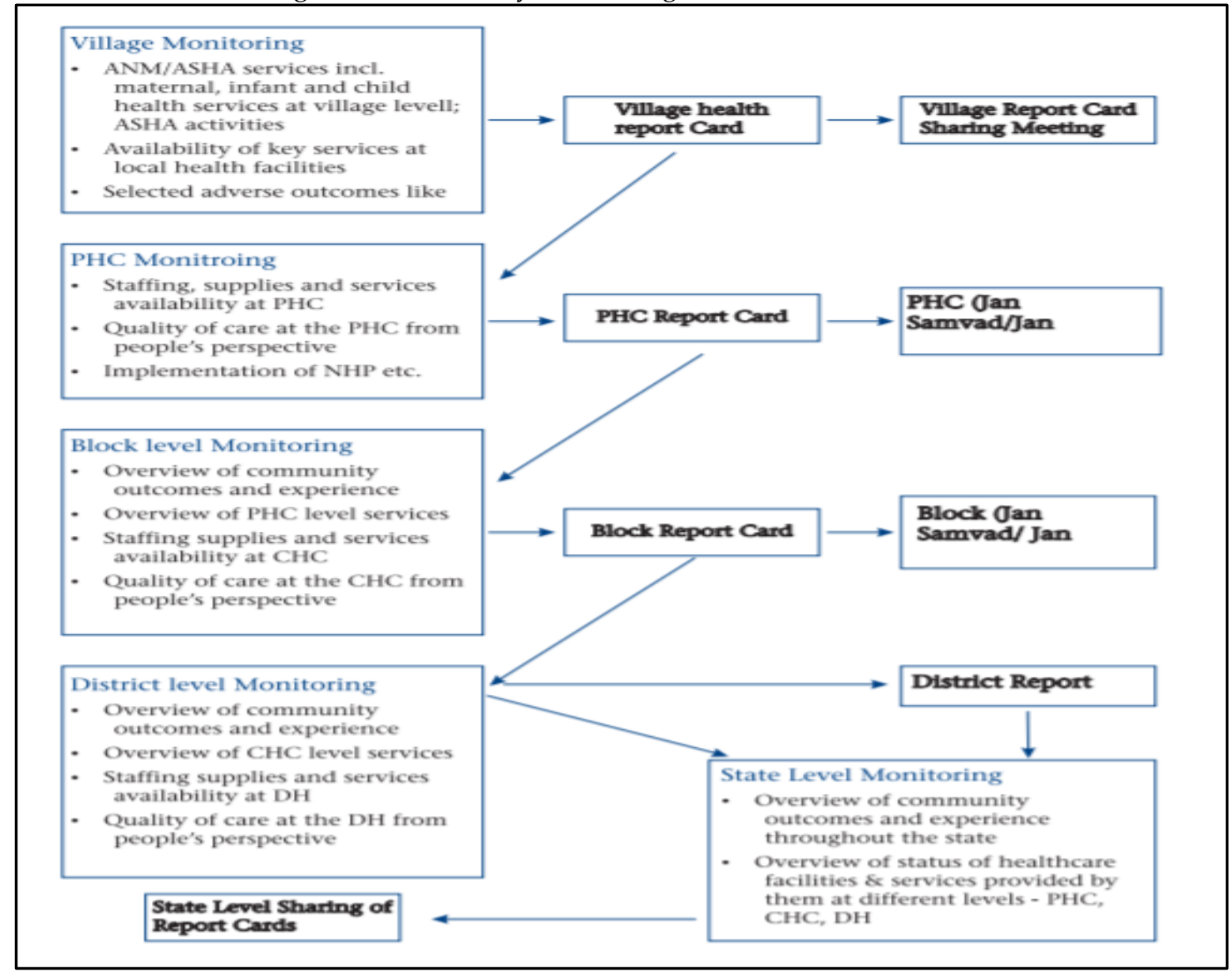

Source: Report of National Secretariat on Community Monitoring 
When we see the role of civil society organizations in developing countries like India, we can easily observe the widespread impact created by these organizations. India had a great history of a diverse and strong civil society movement; it had contributed immensely towards social reforms, education, developing democratic politics, gender issues, agriculture, environment, and healthcare. Even the success of the Indian freedom movement is also attributed to these civil society organizations. After independence, the Indian government continuously used civil society for achieving the development goals. The government involved civil society in every major healthcare scheme, where they played a constructive role in achieving the objectives.

\section{Non-Governmental Organizations (NGO's)}

NGOs are defined as independent organizations working without government intervention. They are classified as operational NGOs and advocacy NGOs. As per the information collated by the Central Bureau of Investigation under the societies registration act, in India, there are 3.2 million (Anand U., 2015) roughly around one NGO per 400 Indians. The government is the biggest contributor for these NGOs followed by the corporate sector funding through corporate social responsibility (CSR) funds. The state of Maharashtra is having the largest presence of NGOs which could be credited to the strong cooperative movement in the state. The healthcare sector has a very large presence of NGOs in India. The impact in healthcare is the collective outcome of direct and indirect interventions by NGOs which means even if an NGO is not registered to work in the healthcare sector it is creating an impact in healthcare. For example-An NGO having the mandate to work for the environment also creating awareness about the ill effects of pollution over human health. This awareness drives motivated stakeholders to come together and take some policy measures for reducing pollution levels. This new policy intervention might have a positive impact on community health indicators.

\section{Community-Based Organizations (CBO's)}

"A community organization is defined as assisting a group of people to recognize their common demands and help them to fulfill those." (Walter W. Pettit, 1925) "Community organization refers to various methods of intervention whereby a professional change agent helps a community action system composed of individuals, groups, or organizations to engage in planned collective action to deal with special problems within the democratic system of values." (Kramer and Specht, 1975) The role of community-based organizations is to work for the welfare of a community. The community is not necessarily a geographical or a social community; it could be a group of individuals having some common problems. For example, a community of AIDS patients, or a community of Acid attack victims. The impact created by these civil society organizations is generally limited to these socially, psychologically, geographically, or digitally connected communities. The types of Civil Society Organizations are Trade unions, Women rights groups, Human rights groups, Child rights groups, Tribal organizations, Farmers welfare organizations \& unions, Organizations for legal aid and awareness, Health awareness groups \& networks, Environmental groups, Consumer rights forums \& organizations, Traders guilds, Cultural organizations, Volunteer action groups, and Sports clubs, etc.

\section{The Future of Civil Society Movement}

The civil society sector in India is very diverse and closely associated with different focus areas; boundaries of these areas sometimes overlap each other and create a zone of interoperability and multidisciplinary action. WEF-KPMG report (World Scenario Series, W. S. 2013; WEF) about civil society and its future (2013) discussed some emerging trends

- Civil society is emerging more vibrant with that, the urge of governments to regulate civil society is also increasing.

- earlier the civil society was seen as the agitators or adversaries of certain sectors, but now industry is working in association with civil society towards their shared objectives.

- The conventional roles of civil society are blurring; which means that civil society organizations are entering into new and more technology-intensive fields.

- Civil society is finding innovative means to communicate their message; they are making great use of social media and the internet. Their reliance on conventional communication mediums is decreasing. 
- Funding models of civil society organizations are now diversifying; they are focusing on becoming more financially sustainable and becoming less dependent on external aid. This is making them a fulltime career option for young professionals.

\section{Involving the Civil Society: Some Policy Decisions}

India's National Health Mission (NHM) has various provisions for ensuring the proper communication and monitoring of health schemes, for this purpose the NHM is having a provision of Community based monitoring (CBM) where NGO's \& CBO's are supposed to work on three objectives:

1. Represent the community and their problems, to educate them about their rights

2. Work on capacity building and training of committee members.

3. Contribute to independent data collection from village to state level.

NGOs and CBOs are assigned with the responsibility of facilitating the process of committee formation at the village, block, and district level, these committees are Rogi Kalyan Samitis (RKS), Village Health Sanitation and Nutrition Committee (VHSNC), Mahila Arogya Samiti (MAS) also the Monitoring and Planning Committees at Primary health centers (PHCs), Community health centers (CHCs) and District Hospitals (DHs), The facilitators from NGOs will undertake the orientation and training of monitoring committee members. We can understand the structure of VHSNC from figure 2 below:

Figure-2: Structure of VHSNC

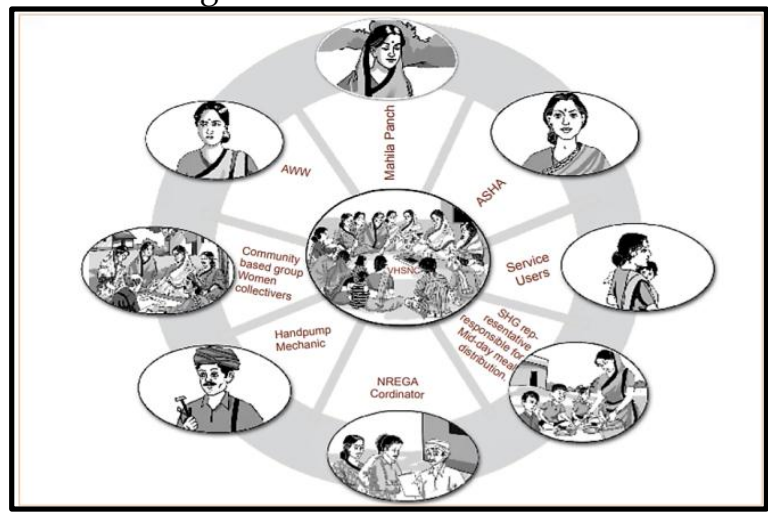

Source: Handbook for Village Health, Nutrition \& Sanitization Committee, NHM
NGOs are screened for the participation in these exercises by using a simple questionnaire any organization with a proven record and experience in concerned sectors will be given priority in the screening process. Outcomes of a study suggest that these organizations play an instrumental role in monitoring the progress, educating the citizens, advocating about rights, and communicating health-related issues to the people. There is also a need of sustaining this progress and to increase the coverage of community engagement in the health sector. Lessons from the implementation of community action for health in India could be useful for other south Asian and middleincome countries. (Lahariya, C., 2020)

Civil Society Organizations Engaged in Health Communication: Case Studies Society for Community Health Awareness Research and Action (SOCHARA)

'SOCHARA is an NGO working in the healthcare sector; it started as an experimental community health cell (CHC) in 1984. CHC is a functional unit of SOCHARA projects.' They started a Centre for Public Health and Equity (CPHE) in 2008 to encourage health equity and social justice, addressing gender issues. They are also working for health-related advocacy and to develop a community-based model for promoting universal healthcare. They also initiated the Community Health Library and Information Centre (CLIC) an online library project and the School of Public Health Equity and Action (SOPHEA) a training and policy research initiative.

SOCHARA has the following focus areas 1. Action 2. Advocacy 3.Training 4.Research 5.Policy Action 6. Communication SOCHARA work extensively in the field of health communication, their communication initiative focuses on developing interactive content promoting community health and health equity, they publish newsletters, research articles and also produce audiovisual content in the form of informative videos. Their network includes 23 NGOs and 1200 participants. SOCHARA's school health program reaches 6000 kids from 300 schools. They are also working in sectors like sanitation and nutrition which also have a positive impact on community health. 
Jan Swasthya Abhiyan (JSA)

Jan Swasthya Abhiyan (PHM-India) is an Indian chapter of PHM Global Network, working in the field of healthcare it was founded in 2000 in Bangladesh, (Indian Chapter in Kolkata) it is headquartered in New Delhi, India. Focus areas for JSA are health equity, sustainable development, and human rights. They developed a framework known as people charter for health which is a document for advocacy and field action by the organization. The charter supports the Alma Ata declaration (Declaration of AlmaAta,1978) and wanted to promote "healthcare as a fundamental human right" in their Cape Town call for action declaration PHM agreed upon to work in collaboration with many organizations around the world for making a global network for health advocacy and action.
The Jan Swasthya Sahyog (JSS)

JSS is a group of health professionals and workers, many of them were trained at leading medical institutions such as AIIMS. They are working in the field of rural healthcare in the Bilaspur District of Chhattisgarh State. The JSS serves the tribal population of the state and it has the reach of 1.5 million people. They cater to over 2500 villages in northwest Chhattisgarh and southeastern Madhya Pradesh they work as a village health center providing villagers access to healthcare facilities. JSS is also working in the health communication sector, they had published a book called Atlas of rural health where they had documented stories, testimonials, and ground reports from the villages of central India. Each story focuses on a particular disease and tries to communicate

Figure-3: Illustration from Atlas of Rural Health (2016)

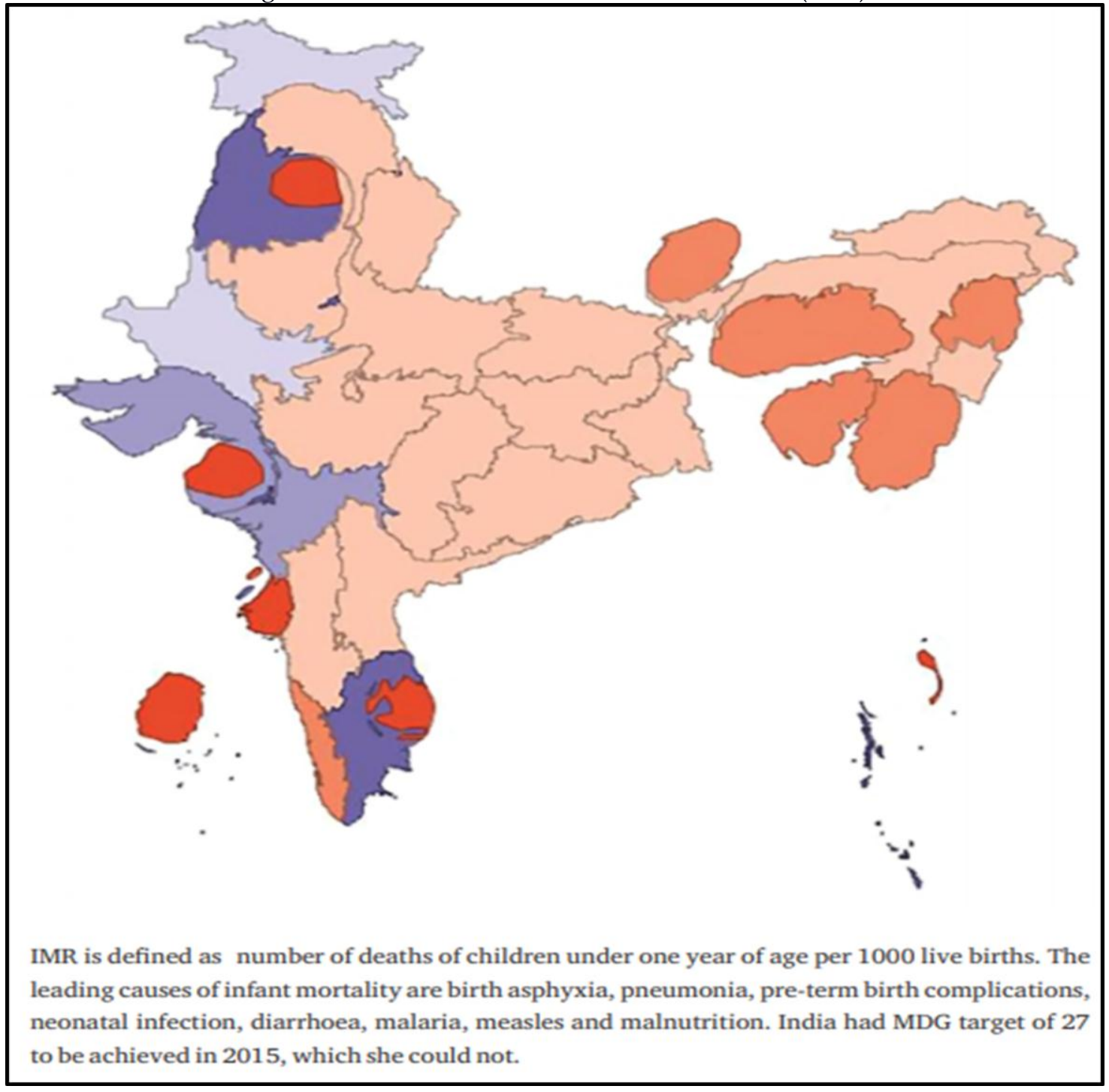

Source: Jan Sawasthya Sahyog, Chhattisgarh 
the need for proper health facilities in rural India. These stories also have real pictures, data, and reports from the ground which make them more compelling. This book can serve as a guide for healthcare professionals working in these rural areas, providing them an insight about the common health problems in the region.

The atlas of rural health (2016) also provides us a glimpse of behavioral and social barriers to be considered by healthcare professionals while working in rural areas. An interesting part of this "atlas" is the maps of inequality where the Indian political map is converted into an infographic. States, where the occurrence of a particular disease is higher, are shown larger than their normal size. This is an innovation and unconventional practice in the field of data representation. As the study of infographics by (Rachel Jacob, 2020) showed that the infographics has an impact over individual's perceptions about health care related threats and problems. Refer to figure 3.

\section{SAMA - Resource Group for Women and Health}

SAMA is a collaboration of various social movements working at regional, national, and global levels. They are working on issues related to women, their health, and their rights. SAMA is working broadly on the subject of access to healthcare. SAMA is driven by the philosophy of providing healthcare as a right to citizens. They also publish field reports and policy briefs their recent and notable policy brief is on the surrogacy bill 2019. SAMA produces a lot of content for health communication which includes posters, articles, and documentary films. Their content is based on subjects like maternal health, Gender-Based Violence, New Reproductive Technologies, Contraceptive Choices and awareness about HIV.

\section{DISCUSSION}

Human health is directly linked with the effectiveness of communication between human beings. As humans started developing complex societies, they started acquiring knowledge. Mere gaining of knowledge is not enough; they need to communicate it for the benefit of others. We can understand it by this example; assume that there is a prehistoric settlement of humans. One member of their group discovered that leaves of certain plants can repel mosquitoes. In this settlement, there is a well-developed communication network.

Figure-4: Poster issued by SAMA for Creating awareness about Gender-Based Violence

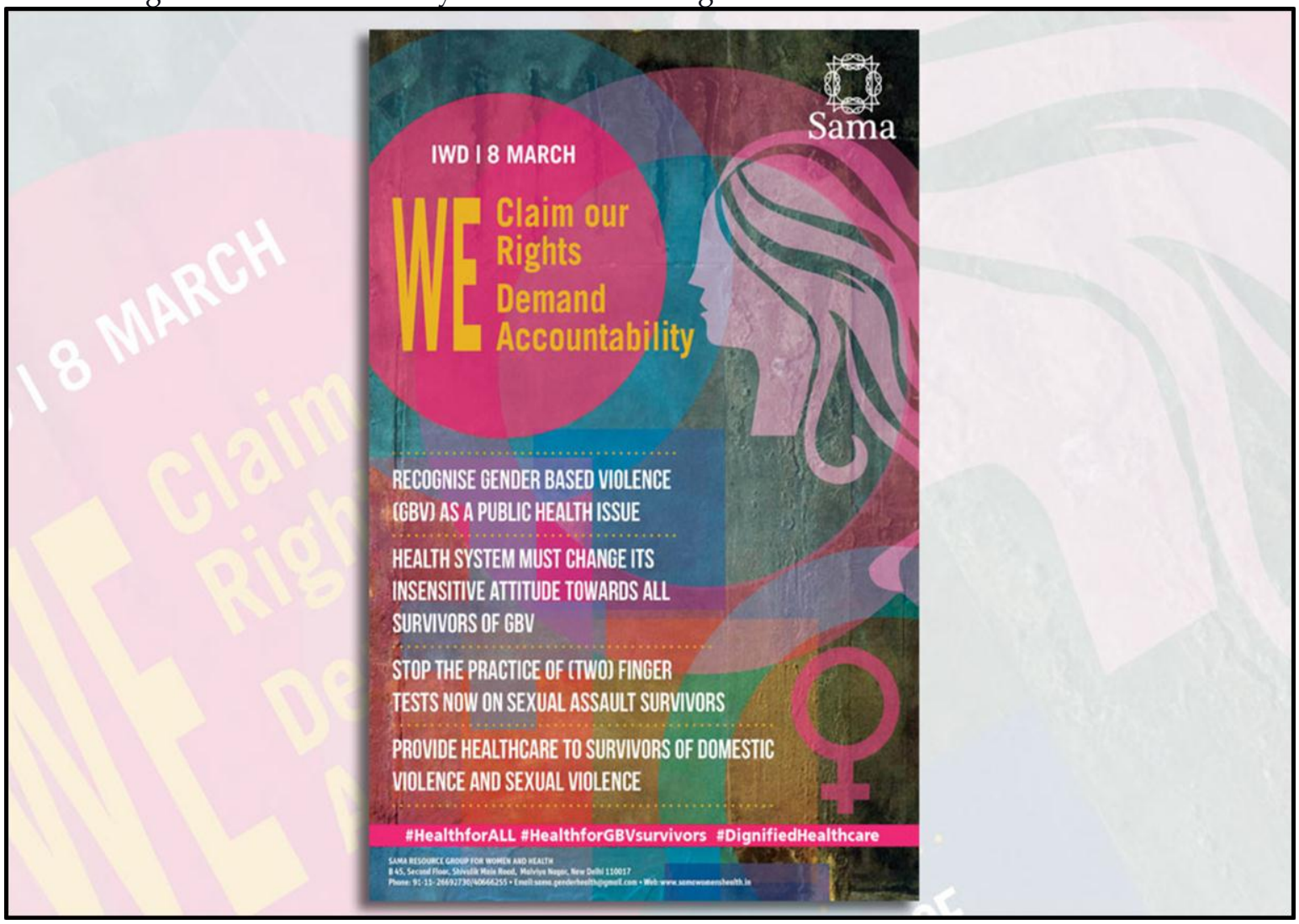

Source: http:/ / www.samawomenshealth.in/ poster-on-gender-based-violence-by-sama/ 
By using that he conveyed his acquired knowledge to every dweller of the settlement. This settlement is now having some better chances to survive against the mosquito-borne diseases as compared to others. This exchange of knowledge is a simple form of health communication. There are multiple examples in modern history as well, which highlights the positive impact of communication over health indicators of society. This relationship between health, communication, and society started operating at a greater level. This is a reason why health communication and the role of civil society in it have become crucial. In developing countries, health indicators are generally not satisfactory. Thus, it is incumbent over the government to work in the direction of improving these indicators. The level of education, connectivity, transportation, and effectiveness of healthcare systems contribute towards developing a social understanding of healthcare. This understanding or perception of masses about the health systems directly reflects in their health-related decisions.

The role of civil society in health communication comes when there is a requirement to modulate the existing perception of masses; either to make them more receptive to healthcare programs or to increase their participation in the activities related to public health such as vaccination drives. It is evident that involving civil society in health communication has a positive impact on the delivery of healthcare facilities. Civil society has a greater reach and acceptability in the underprivileged section of the society; this reach usually assists the government in communicating health-related information easily to these groups. In India, there is still a great scope of including civil society at multiple levels of policymaking. Involving civil society will improve the outcomes and coverage of health schemes.

The Indian healthcare system is dealing with the problem of inefficiency and corruption, and civil society will help in dealing with these problems as well. The concept of social audit of government schemes could be implemented more thoroughly. Citizens will become more aware of their rights and they will constructively contribute to ensuring the delivery of healthcare services.

\section{CONCLUSION}

Our analysis suggests that civil society in India played a very important role in communicating health to the masses. In a developing country like India providing proper healthcare to the citizens is one of the greatest priorities of the government, but the resources and expertise with the government are limited. We recommend a greater involvement of civil society organizations in health communication. Regular feedback from the civil society will help the policymakers to understand real problems, and also aid them to fine-tune their schemes, campaigns, and content according to people. The monitoring of government schemes is also a great challenge; constant communication with the civil society will also contribute to proper monitoring and execution of these schemes.

\section{REFERENCES}

Alati, Paulo, LimeiraHermínio, G., Marcondes, S. S., \& Paulo, L. S. (2020). SOCIAL MEDIA AND PROTESTS ENGAGEMENT: WHAT' $S$ GENDER GOT TO DO WITH IT? 11. https://doi.org/10.31620/JCCC.6.20/03

Alma Ata Declaration, (September 1978), 6-8. Retrieved from https://www.who.int/publications/alma ata_declaration_en.pdf

Amrith, S. S. (2009). Health in India Since Independence February 2009 BWPI Working Paper 79, (February), 1-27. Retrieved from https://pdfs.semanticscholar.org/d7e4/8 2ff96cdf5fde51c3 fba91e9eb5f037c2dae.pdf

Anand, S., \& Fan, V. (2016). THE HEALTH WORKFORCE INDIA, (16). Retrieved from

https://www.who.int/hrh/resources/160 58health_workforce_India.pdf

Anat, D. S., Ha, J. F., Hons, M., Longnecker, N., Charles, (2010). Doctor-Patient communication: A Review, 38-43. Retrieved from https://www.ncbi.nlm.nih.gov/pmc/ articles/PMC3096184/pdf/i1524-5012-101-38.pdf

Arnold D., (1986). CHOLERA AND COLONIALISM IN BRITISH INDIA *, 118-151. 
Curtin, B. (2006). Semiotics and Visual Representation Semiotics and Visual Representation, 51-62. Retrieved from http:/ / www.arch.chula.ac.th/journal/file s/article/1JjpgMx2iiSun103202. pdf

index1 @ nhm.gov.in. (n.d.). Retrieved from https://nhm.gov.in/index1.php?lang=1\&l evel $=2 \&$ sublinkid $=172 \&$ lid $=246$

indianexpress.com, (2015). Retrieved from https://indianexpress.com/article/india/ india-others/india-has-31-lakh-ngostwice-the-number-of-schools-almosttwice-number-of-policemen/

Jan Swasthya Sahyog, Atlas of Rural Health (2016) Retrieved from http://www. jssbilaspur.org/ wordpress/wp-content/ uploads/2016/09/ Atlas-of-Rural-Healthwith-Cover.pdf

Kramer, R. and Specht, H. (Eds.). (1975). Readings in Community Organization Practice

Kushwaha, B. P. (2020). INTEGRATING SOCIAL MEDIA AND DIGITAL MEDIA AS NEW ELEMENTS OF INTEGRATED MARKETING COMMUNICATION FOR CREATING, 11(2019). https://doi.org/ 10.31620/JCCC.06.20/05

Lahariya, C., Roy, B., Shukla, A., Chatterjee, M., Graeve, H. De, Jhalani, M., \& Bekedam, H. (2020). Community action for health in India: evolution, lessons learnt and ways forward to achieve universal health coverage

Mosadeghrad, A. M. (2014). Original Article Factors influencing healthcare service quality, 3(2), 77-89. https://doi.org/ 10.15171/ijhpm.2014.65

Mosharafa, E. (2015). All you Need to Know About: The Cultivation theory, 15(8). Retrieved from https://globaljournals.org/GJHSS_Volum e15/3-All-you-Need-to-Know.pdf

National conference of social work, Denver, 1925, Chicago: University of Chicago Press 1925, p. 682.

Neumann E.N, (1974), Spiral of silence theory, Retrieved from https://noelleneumann.de/ scientific-work/spiral-ofsilence/
Rao, K.D, (2017) FROM BRAIN DRAIN TO BRAIN GAIN MIGRATION OF NURSING AND MIDWIFERY WORKFORCE. Retrieved from https://www.who.int/workforcealliance /brain-drain-brain-gain/Migration-ofnursing-midwifery-inKeralaWHO.pdf?ua=1

Frost, R., Goodin, R.E, Pettit P., Pogge T. (2017.). Retrieved from https:// onlinelibrary.wiley. com/doi/pdf/10. 1002/9781405177245.ch19

Original essential health services framework (a) www.cdc.gov. (n.d.). Retrieved from https:// www.cdc.gov/publichealthgate way/publichealthservices/originalessenti alhealthservices.html

Riegelman, R., (2001), Health Information Systems and Health Communications: Narrowband and Broadband Technologies as Core Public Health Competencies, 1179-1183. Retrieved from https://www. ncbi.nlm.nih.gov/pmc/articles/PMC1446 739/pdf/0911179.pdf

Phmovement.org. (n.d.). Retrieved from https://phmovement.org/about-3/

Raingruber, B. (2004). Health Education, Health Promotion, and Health: What Do These Definitions Have to Do with Nursing? 1-24. Retrieved from http:// samples.jbpub.com /9781449697211/28123 _CH01_Pass2.pdf

Razinah, N., \& Zain, M. (2017). Agenda Setting Theory, (January 2014).

Reshmi R. S, Gupta, M. K., Kumar, D., \& Visengrawala, F. (2015). An intervention to empower and engage the self-help groups for menstrual hygiene in Karnataka , India, 4(1), 15-22. https://doi. org/10.5455/2320-1770.ijrcog20150203

Stewart, M. A. (1995). EFFECTIVE PHYSICIAN-PATIENT COMMUNICATION AND HEALTH OUTCOMES: A REVIEW, 152(9), 14231433. Retrieved from https://www.ncbi. nlm.nih.gov/pmc/articles/PMC1337906/ pdf/cmaj00069-0061.pdf

Walter W. Pettit (1925): Case Studies in Community Organization. Social Service Review 149-150. 
who.int. (n.d.). Retrieved from https://www.who.int/activities/preventi ng-noncommunicable-diseases/

who_we_are @ sochara.org? (n.d.). Retrieved from https://sochara.org/who_we_are

World Scenario Series, WEF (2013). The Future Role of Civil Society, (January). www.samawomenshealth.in. (n.d.). Retrieved from http://www.samawomenshealth. in/about-us/

www.samawomenshealth.in. (n.d.). Retrieved from http://www.samawomenshealth. in/poster-on-gender-based-violence-bysama/ 